\title{
Bait formulations and longevity of navel orangeworm egg traps tested
}

\author{
by L.P.S. (Bas) Kuenen, Walt Bentley, \\ Heather C. Rowe and Brian Ribeiro
}

\section{Standardization of pest monitoring} practices and materials to maximize sensitivity to pest populations in the field is a foundation of effective integrated pest management (IPM). In response to changes in the availability of commercial bait material for navel orangeworm (NOW) egg traps, we evaluated potential alternative bait materials for use in monitoring this key pest of almonds, pistachios, walnuts and figs. Navel orangeworm egg traps baited with uninfested nutmeats were as effective as almond meal plus $10 \%$ crude almond oil, whereas traps baited with freezekilled, navel orangeworm-infested nutmeats were less effective. The use of nut mummies (culled during winter orchard sanitation) as trap bait may not produce consistent results since the level of navel orangeworm infestation of these nuts is typically unknown. Three seasons of field tests showed that egg traps baited with almond meal plus $3 \%$ or $10 \%$ crude almond oil received similar numbers of navel orangeworm eggs, and these traps were equally effective for at least 10 weeks.

W hen navel orangeworm (NOW) infests nuts and figs, they will contain larvae or pupae and fecal material of the pest. Likewise, navel orangeworm infestation is highly correlated with the infection of nuts by Aspergillus spp., which produce carcinogenic aflatoxins. Both result in losses for growers.

Navel orangeworm (Amyelois transitella) larvae enter figs or nuts through open ostia (figs) or holes in damaged nut hulls (especially codling moth en-

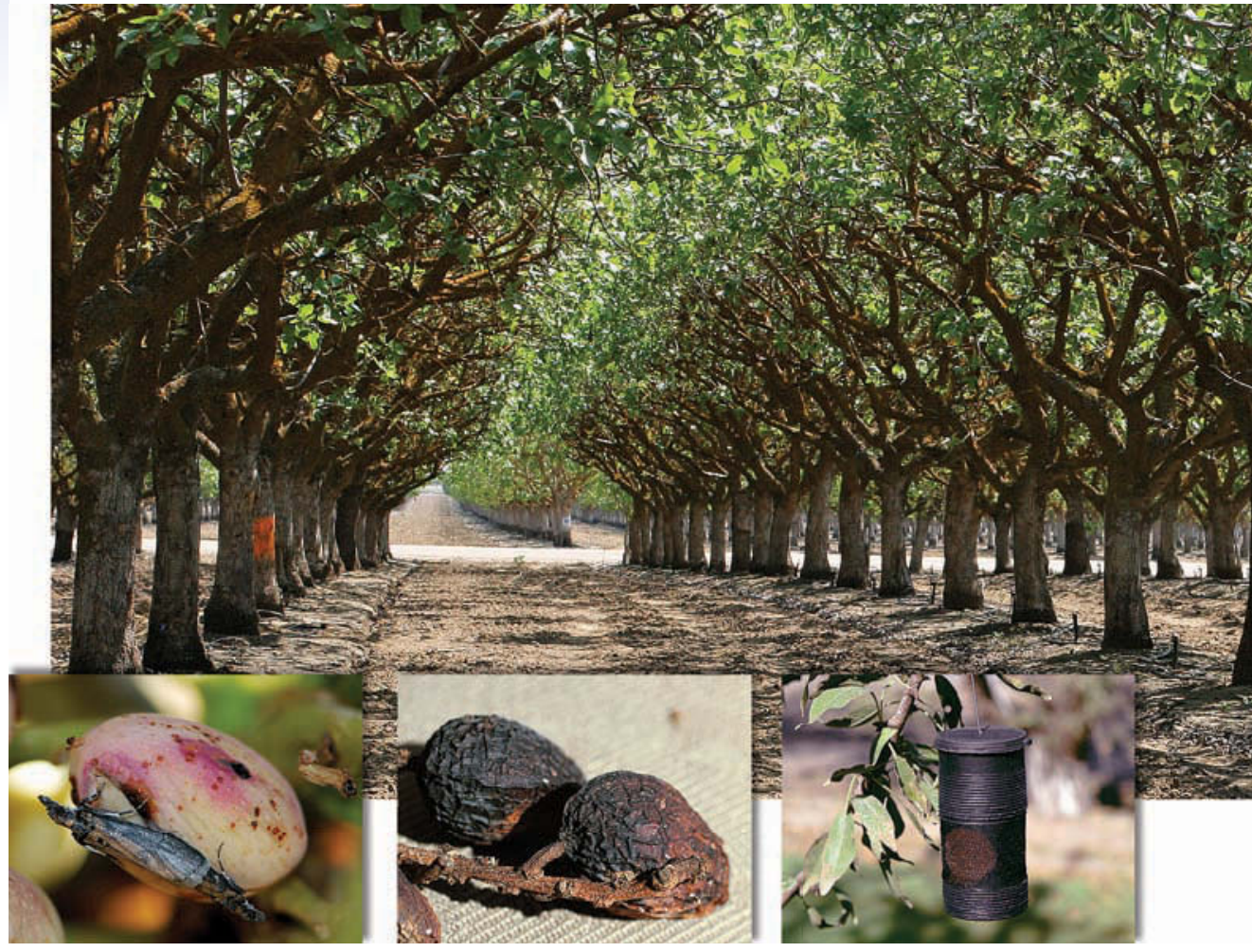

Top, a pistachio orchard in Kings County. Above left, an adult navel orangeworm pair mating on a pistachio; center, naval orangeworm lay their eggs on mummy nuts in the spring; right, egg traps are used in orchards to monitor navel orangeworm for integrated pest management.

trance wounds in walnuts); they also enter after hull-splitting and drying of almonds, pistachios and walnuts, which occurs normally as these nuts mature.

It is believed that navel orangeworm lay eggs on susceptible hosts in response to changes in odors - associated with the physical maturity changes - emitted from the nuts and figs, and possibly in response to altered tactile cues associated with these physical changes. The host odors are attractive to female navel orangeworm, which then lay eggs on the host; mated navel orangeworm females are known to fly upwind to odors from crude almond oil (CAO) (Phelan and Baker 1987).

The ability to monitor pests is a key component of any integrated pest management (IPM) program. The navel orangeworm is a primary pest of about 1.1 million acres of nuts and figs in California, and currently it is monitored by direct counts of eggs or larvae on the host and by navel orangeworm egg traps (Rice et al. 1976). Trapping data is used to time the early harvest of almonds prior to egg-laying by the third generation of navel orangeworm and for timing insecticide sprays for the third generation in pistachios (Bentley and Surber 1986). The more accurately navel orangeworm populations can be tracked, the better they can be managed, particularly with newer, reducedrisk insecticides that have shorter residual times or require more precise application timing to maximize their effect on navel orangeworm numbers. Although the sex pheromone for this insect has been reported (Coffelt et al. 1979; Leal et al. 2005; Millar and Kuenen 2005), it is ineffective in sticky traps compared to traps baited with unmated females (Kuenen et al. 2001; Millar and Kuenen 2006). Therefore, egg traps will remain important for years to come in the IPM of navel orangeworm.

Current commercial egg traps consist of plastic vials (3.375 inches by 
1.625 inches, with three 1.125-inch, screened, round holes in the lower half of the vial) containing a bait attractive to navel orangeworm females, which elicits egg-laying on the surface of the traps. When first introduced, the traps were baited with a mixture of wheat bran, honey, glycerol and water. The traps' efficiency has since been improved by adding ridges around the traps, painting them black and changing the bait from a wheat-branbased material to almond press cake (an almond-oil processing byproduct) (Van Steenwyk et al. 1986). These black traps, baited with almond press cake plus crude almond oil ( $10 \%$ by weight), have become a de facto standard for navel orangeworm monitoring.

However, in 1997 Liberty Vegetable Co. (Santa Fe Springs, Calif.), the provider of almond press cake, altered its almond-oil processing and now sells almond meal instead of almond press cake as a byproduct. In 2001, we initiated field tests to find the optimum blend of almond meal plus crude almond oil to attract navel orangeworm females, and used red wheat bran as a crude almond oil carrier for comparison. We also investigated the relative attractiveness of infested versus uninfested almond and pistachio nutmeats, because infested almonds are reportedly better attractants for navel orangeworm than uninfested nuts (Andrews and Barnes 1982).

\section{Egg trap tests}

Tests were conducted in almond, fig and pistachio orchards in Madera County during the 2001 to 2003 growing seasons. Navel orangeworm egg traps were purchased from Trécé, Inc. (Adair, Okla.) and were filled at least $75 \%$ with baits to ensure that the traps' windows remained covered with bait throughout the test periods (see also Van Steenwyk et al. 1986). Traps were suspended on branches about 5 feet above the ground in the outer half of the canopy, and treatments were placed in randomized complete block designs with five or more replicates per test. Each replicate block was laid out along tree rows with at least 65 feet between traps within the replicate blocks and at least 65 feet between replicate blocks (actual spacing was determined by tree spacings within and between rows). The first trap in each row was at least 165 feet in from the nearest orchard road. All test blocks consisted of areas with no orchard drive rows or any other open spaces within larger orchard blocks.

Typically, egg counts were taken at weekly intervals. After each count, traps were re-randomized by moving them one tree forward within the replicate, and then the last trap in the row was moved to the first trap position in the same row. Trap baits were always formulated in the Kuenen lab, but plot specifics and the choice of orchards were conducted independently by our labs to ensure adequate orchard representation.

Data were analyzed graphically and by ANOVA. No data transformations were necessary as indicated by Bartlett's test for homogeneity of variances (Sokal and Rohlf 1981). Egg counts (eggs/trap/week) were analyzed by 2-way ANOVA using PROC GLM in SAS, and mean separation tests (alpha $=$ 0.05) were conducted with Tukey's HSD test (SAS 2001). No significant block effects were found in any of our studies $(P>0.05)$.

\section{Nutmeats vs. almond meal plus oil}

Since some growers and pest control advisors use nutmeats collected from orchard sanitizing procedures in their egg traps, our first test in 2001 compared traps baited with (1) almond pieces, (2) pistachio pieces, (3) navel orangeworm-infested almond pieces, (4) navel orangeworm-infested pistachio pieces, (5) almond meal plus $10 \%$ (by weight) crude almond oil or (6) left empty as control traps. For the infested nut pieces, navel orangeworm larvae had been freeze-killed (as they would be by users of culled mummy nuts).

There were no differences in trap catch among uninfested almond, uninfested pistachio or traps baited with crude almond oil $(P>0.05)$ (fig. 1), whereas traps baited with infested almond or infested pistachio pieces were significantly lower $(P<0.05)$ than uninfested almond pieces. The control traps received few eggs. Commercial bait is easier to handle and more easily standardized. Further, since the almond meal containing $10 \%$ crude almond oil was as effective a trap bait as the uninfested nutmeats, and since the components are easily manipulated, our subsequent tests focused on assessing the influence of varying amounts of

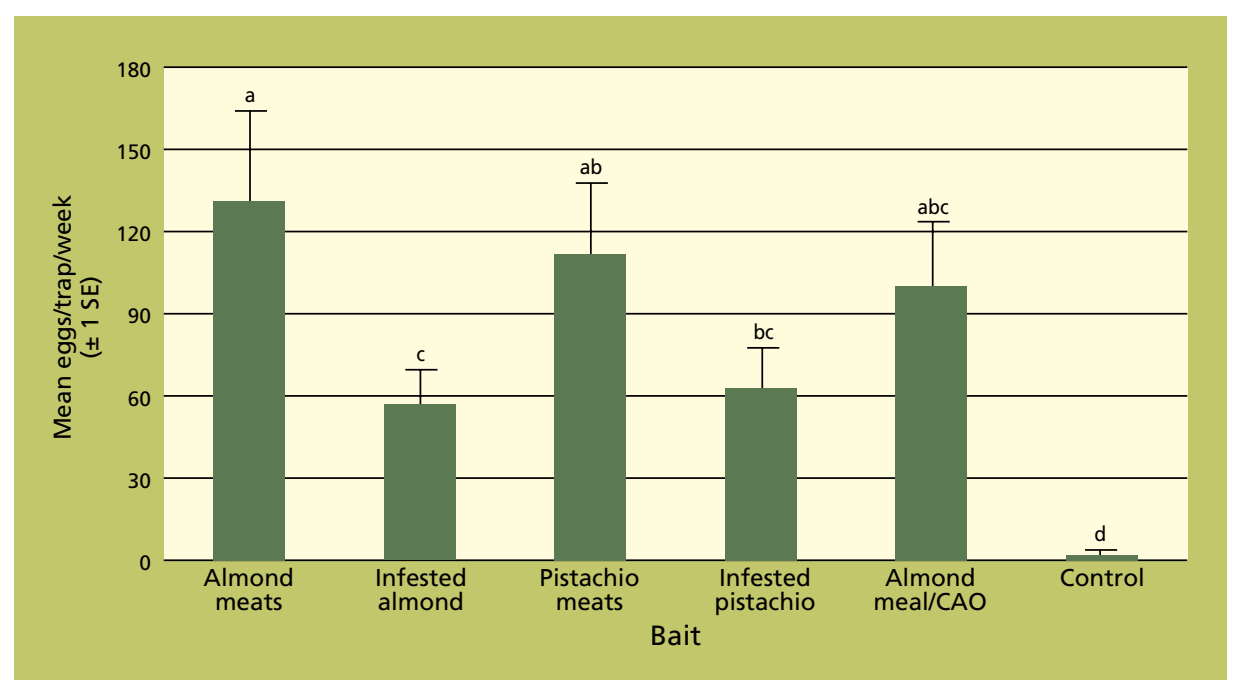

Fig. 1. Mean navel orangeworm (NOW) egg counts from traps containing NOW-infested almond or pistachio nutmeats, uninfested almond or pistachio nutmeats, almond meal plus $10 \%$ crude almond oil (CAO) by weight of almond meal, or unbaited controls. Traps were hung in a Madera County fig orchard March 26-April 30, 2001, with one trap per bait type in each of five blocks for a total of 30 traps. Traps were checked weekly. Bars represent \pm one standard error. Columns having no letters in common are significantly different; $P<0.05$, Tukey's HSD test. 


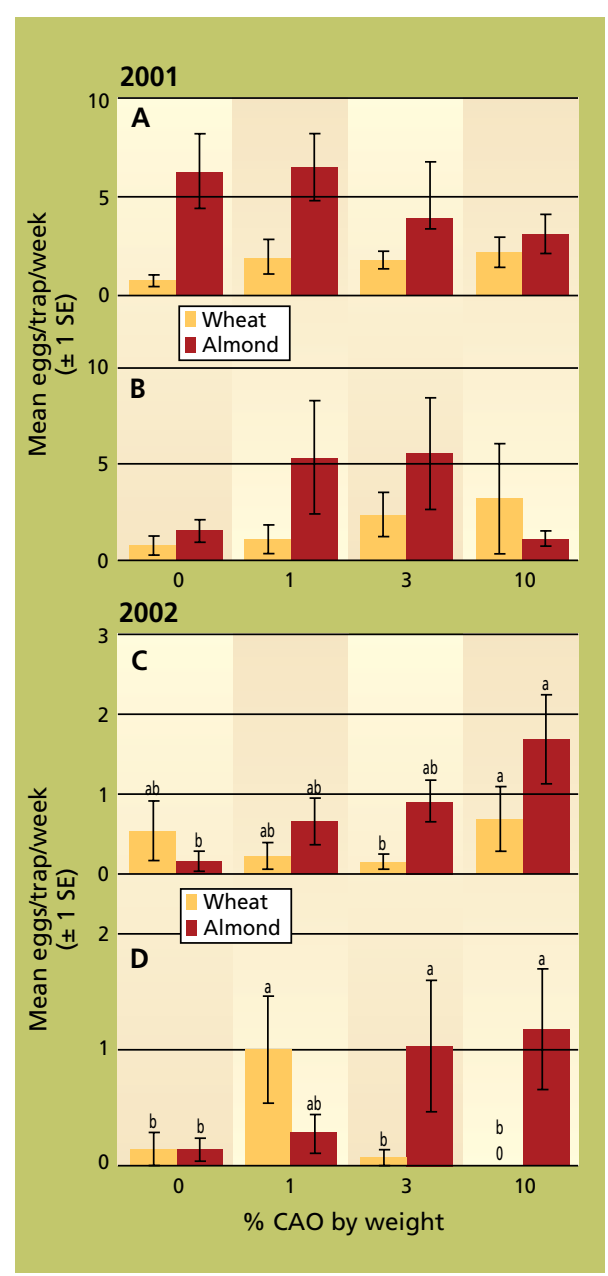

Fig. 2. Mean navel orangeworm (NOW) egg counts from egg traps containing almond meal or wheat bran plus crude almond oil (CAO). In 2001, traps were hung in a Madera County (A) almond orchard May 17-23 and checked daily, and (B) pistachio orchard July 11-Aug. 1 and checked weekly. In both orchards, one trap per bait type was hung in each of five blocks for a total of 40 traps. In 2002, traps were hung in a Madera County (C) pistachio orchard Aug. 8-Sept. 5, and (D) almond orchard Oct. 8-Nov. 5. In both orchards, one trap per bait type was hung in each of seven blocks for a total of 56 traps, and checked weekly. In 2001, there were no significant differences in egg counts within bait types. In 2002, columns having no letters in common are significantly different within bait types; $P<0.05$, Tukey's HSD test. All bars represent \pm one standard error.

crude almond oil plus almond meal on trap capture.

\section{Standardizing trap baits}

Comparisons were made between traps baited with almond meal or red wheat bran mixed with $0 \%, 1 \%, 3 \%$ or $10 \%$ crude almond oil by weight, based on the weight of almond meal. Thus, traps with a given percentage of crude almond oil contained the same amount of crude
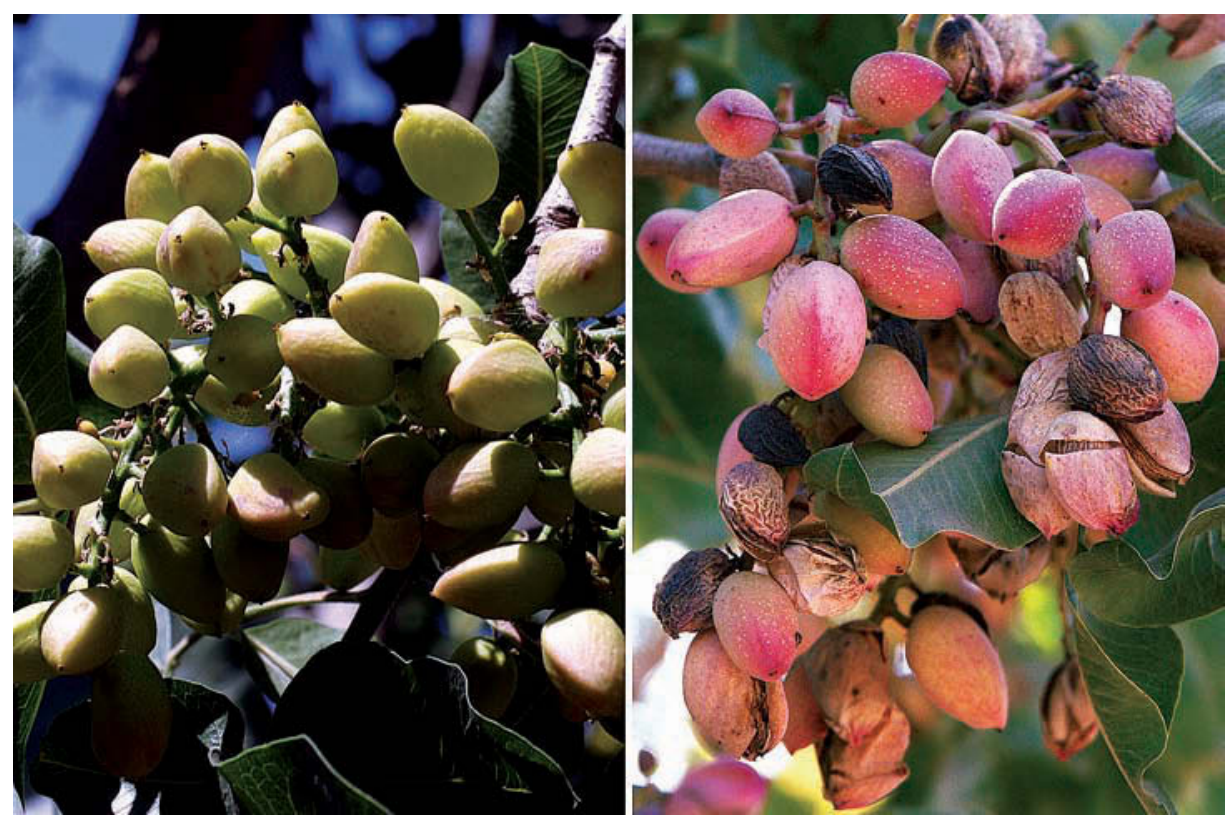

Monitoring with egg traps allows growers to better time harvests and more effectively apply lower-risk insecticides. Left, a midseason pistachio cluster and, right, nuts mummifying after harvest.

almond oil whether mixed with almond meal or the less-dense wheat bran.

Our first test with almond meal and wheat bran plus crude almond oil indicated that traps baited with almond meal plus $0 \%$ or $1 \%$ crude almond oil received more eggs than traps baited with almond meal plus $3 \%$ or $10 \%$ crude almond oil, and more than all wheatbaited traps $(P<0.05)$ (fig. 2A). In this first test, however, traps were checked daily, whereas in all subsequent tests eggs were counted weekly, which is typical for navel orangeworm monitoring.

A subsequent test in 2001 indicated that traps baited with almond meal plus $1 \%$ or $3 \%$ crude almond oil received more eggs compared to traps without crude almond oil or traps baited with wheat bran $(P<0.05)$ (fig. 2B). Overall, traps baited with almond meal plus crude almond oil received significantly more eggs than traps baited with wheat bran plus crude almond oil $(P<0.05)$. In 2002 , we tested the same treatments but at different times during the growing season and in different orchards (which likely accounts for the lower numbers of eggs per trap compared to 2001). There was a clear trend for higher egg counts on traps with higher amounts of almond meal plus crude almond oil, whereas traps with crude almond oil on wheat bran showed no trend in trap capture in relation to the dosage of crude almond oil (figs. 2C, D).

In 2003, we conducted two further tests of almond meal plus crude almond oil only, since the wheat bran plus crude almond oil baits typically captured fewer eggs. Trap capture data were combined for the two tests and showed nearly equal trap catch at all doses of crude almond oil tested $(P>0.05)$ (fig. 3 ).

In this last study and our first with almond meal plus crude almond oil, the treatment without crude almond oil was as good as or better than those with crude almond oil. This is perplexing, since all the almond meal and crude almond oil came from single batches, respectively, from the vendor. It is also important to note that in all our tests, trap capture variability was high and mean trap catch in relation to the dosage of crude almond oil shifted continuously. Even with replicated and repeated tests, consistent significant differences were rare. Nevertheless, over the course of all tests, treatments with almond meal plus $3 \%$ crude almond oil typically performed well, so we are compelled to recommend it as the best treatment in this monitoring technique.

\section{Trap bait longevity}

In summer 2003, we also examined the longevity of trap baits. Fifteen traps were baited with $3 \%$ crude almond oil and 15 with $10 \%$ crude almond oil on 


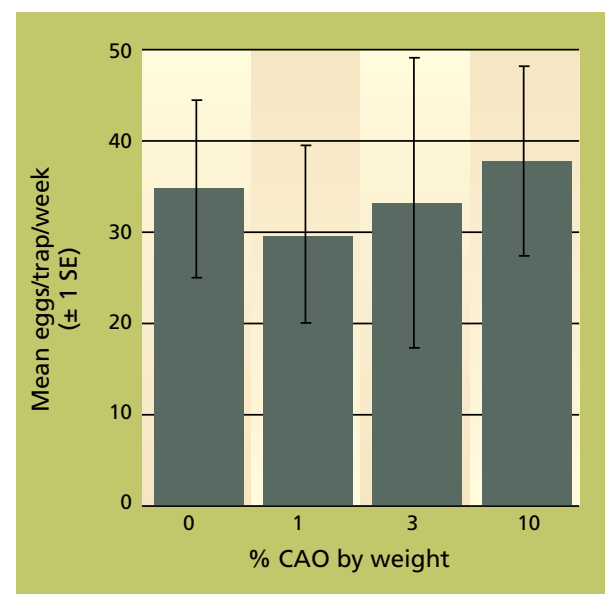

Fig. 3. Mean navel orangeworm (NOW) egg counts from egg traps containing almond meal plus crude almond oil (CAO). Traps were hung concurrently in a fig and pistachio orchard in Madera County May 20-June 26, 2003. In each orchard, one trap per bait type was hung in each of five blocks for a total of 80 traps, and checked weekly. Bars represent \pm one standard error; there were no significant differences in egg counts.

almond meal, and aged (held) in a laboratory incubator at $90^{\circ} \mathrm{F}$. Every 2 weeks, five traps of each dosage were removed and held at $-4^{\circ} \mathrm{F}$ until we had traps that were aged at $90^{\circ} \mathrm{F}$ for $0,2,4$ and 6 weeks $\left(-4^{\circ} \mathrm{F}\right.$ is a standard laboratory freezer temperature, at which little or no evaporation of odor compounds occurs). For this test, traps of all age categories were placed in a fig orchard when day-time highs were regularly $90^{\circ} \mathrm{F}$ to $95^{\circ} \mathrm{F}$. Traps were positioned in a randomized complete block design and egg counts were taken weekly for 4 weeks. There were no differences in the capture efficiency of these aged egg traps $(P>0.05)$ (fig. 4$)$ even after aging in the lab for 6 weeks and use in the field for 4 weeks.

\section{Practical implications}

Tests over three field seasons and in several orchards demonstrated that almond meal mixed with crude almond oil is an effective trap bait, and traps baited with a near-neutral carrier (wheat bran) plus crude almond oil were not as effective $(P<0.05)$. In addition, traps baited with pistachio or almond nutmeats were as effective as almond meal plus crude almond oil; however, freeze-killed, navel orangeworm larvae-infested nuts captured significantly fewer eggs $(P<0.05)$.

The variability in egg counts on the

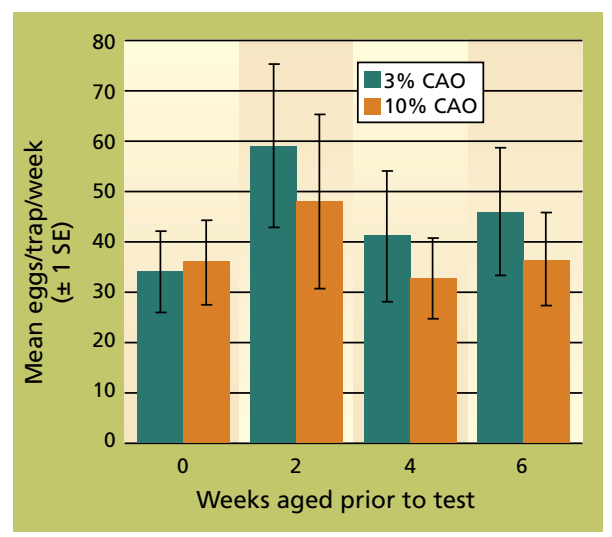

Fig. 4. Mean navel orangeworm (NOW) egg counts from egg traps containing almond meal plus $3 \%$ or $10 \%$ crude almond oil (CAO) by weight of almond meal; traps with baits had been aged $0,2,4$ or 6 weeks in a laboratory incubator. Traps were hung in a Madera County pistachio orchard May 2-29, 2003. One trap per bait type was hung in each of five blocks for a total of $\mathbf{4 0}$ traps, and checked weekly. Bars represent \pm one standard error; within bait types there were no significant differences in egg counts.

traps was always high, with the standard errors typically exceeding the means. Although significant differences in trap counts were rare among the almond meal/crude almond oil baits, traps with almond meal plus 3\% or $10 \%$ crude almond oil tended to capture the greatest number of eggs, and both traps were equally effective over 10 weeks. We conclude that almond meal plus 3\% crude almond oil will be effective in the field, with little or no loss of efficiency for at least 10 weeks.

\section{References}

Andrews KL, Barnes MM. 1982. Differential attractiveness of infested and uninfested mummy almonds to navel orangeworm moths. Environ Entomol 11:280-2.

Bentley WJ, Surber E. 1986. Chemical control studies on navel orangeworm in pistachio. California Pistachio Commission Production Research Reports, Crop Year 1985-1986. www.acpistachios.org/ research.php. $p$ 75-6.

Coffelt JA, Vick KW, Sonnet PE, Doolittle RE. 1979. Isolation, identification, and synthesis of a female sex pheromone of the navel orangeworm, Amyelois transitella (Lepidoptera: Pyralidae). J Chem Ecol 5:955-66.

Kuenen, LPS, Rowe HC, Steffan K, et al. 2001 Incomplete female sex pheromone of the navel orangeworm, Amyelois transitella. California Pistachio Commission Production Research Reports, 2001-2002. www.acpistachios.org/research.php. $96 \mathrm{p}$.

Leal WS, Parra-Pedrazzoli AL, Kaissling KE, et al. 2005. Unusual pheromone chemistry in the navel

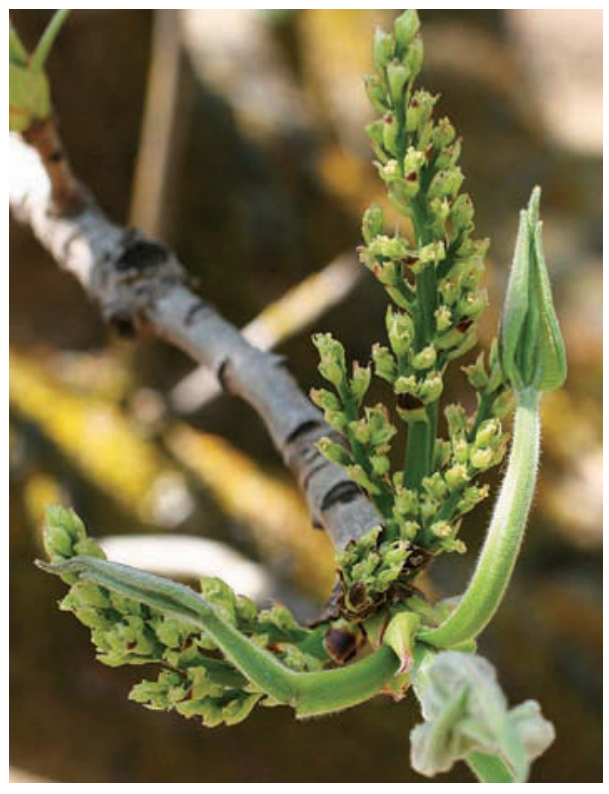

A new formulation of almond meal mixed with crude almond oil was an effective trap for navel orangeworm eggs. Above, female pistachio flowers.

L.P.S. (Bas) Kuenen is Research Entomologist, U.S. Department of Agriculture Agricultural Research Service, San Joaquin Valley Agricultural Sciences Center, Parlier; W. Bentley is IPM Entomologist, UC Statewide IPM Project, UC Kearney Agricultural Center, Parlier, H.C. Rowe is Graduate Student, Department of Plant Sciences, UC Davis; and B. Ribeiro is Staff Research Assistant, UC Statewide IPM Project. This research was supported in part by grants from the California Pistachio Commission. We thank all our cooperating growers for access to their orchards.

orangeworm: Novel sex attractants and a behaviora antagonist. Naturwissenschaften 92:139-46.

Millar JG, Kuenen LPS. 2005. Field and laboratory studies to improve pheromone of navel orangeworm. Proceedings/Annual Report of California Pistachio Commission. www.acpistachios.org/research.php. p 127-40.

Millar JG, Kuenen LPS. 2006. Field and laboratory studies to improve pheromone of navel orangeworm. Proceedings/Annual Report of California Pistachio Commission. www.acpistachios.org/research.php.

Phelan PL, Baker TC. 1987. An attracticide for control of Amyelois transitella (Lepidoptera: Pyralidae) in almonds. J Econ Entomol 80:779-83.

Rice RE, Sadler LL, Hoffman ML, Jones RA. 1976. Egg traps for the navel orangeworm, Paramyelois transitella (Walker). Environ Entomol 5:697-700

Sokal RR, Rohlf FJ. 1981. Biometry (2nd ed.). New York: WH Freeman. $776 p$.

Van Steenwyk RA, Barnett WW, Bentley WJ, et al. 1986. Improved NOW egg traps. Cal Ag 40(1):24-5. 